\title{
A carne crua \\ (de um modo poético do pensamento)
}

Alberto Pucheu

Uma das características daqueles que pensam poeticamente é a confiança nos efeitos da linguagem, conquistada pela experiência dos movimentos aos quais, ao longo da vida, sobretudo quando à revelia deles, a força de alguns arranjos de palavras os obrigam, transformando o presente em futuros indetermináveis. Sem a violência de um sentido inesperado sobre a pessoa, sem a coação desse prévio exterior a impor um lance de confusão ao que era interior, sem esse veloz impacto de uma subitaneidade desestruturante das fixidades, não há poético. Nesse lance de confusão, vazador da linha de exclusão entre exterior e interior, nessa instauração de uma zona de mútua permeabilidade, principia o pensamento.

Para quem se dedica a ela, a linguagem poética é afeita às implicações (não às explicações), às instabilidades (não às estabilidades), levando, constantemente, o dedicado de uma posição a outra, de uma criação a outra, pois os lugares então surgidos são invenções que o poético realiza através do pensador, abrindo, por ele, nele, nessa nova zona de permeabilidade, uma inindividualização que garante, simultaneamente, um tipo não antecipável de reindividualização. É o poético que fabrica as individualidades de quem participa de seu jogo, não o inverso.

A exploração desse âmbito de sujeição às acelerações das mudanças, esse ato de aventura e instigação perpetrado pela voz aceleradora de qualquer movimento - inventando uma diagonal de legibilidade atuante, onde uma nova possibilidade cabe somente nas palavras que, por sua vez, afetam o cotidiano, transformando-o -, é a tarefa dos pensadores poéticos. Como se eles mostrassem que o beco sem saída pode até existir na rua aqui do lado, mas não nos intermináveis fluxos do pensamento, nos quais, com um veleiro sem velas*, tudo é correntezas de marés, profundidades, brilhos de superfícies, onde tudo é futuro, onde tudo é a exuberância de algum transbordamento que jamais deixa as viagens se deterem.

" (Lima, Jorge de. "Invenção de Orfeu". Em: Poesia Com. pleta, vol. 2. Rio de Janeiro: Nova Fronteira, 1980: 28) 
Por exemplo: uma ilha nunca estanca - mesmo quando aparentemente parada, sua suposta imobilidade é uma das alterações rítmicas de um movimento às vezes imperceptível, porém constante, acentuando a importância de uma microscopia da mutabilidade através da linguagem. Ela, a ilha, não transborda do mar para anunciar um ponto de chegada - lar pacífico - ao navegante, mas um começo, uma combativa zona de imprevisibilidade: "ilha movediça,/móvel terra, céu incerto/ mundo jamais descoberto"*. Nunca se descobre uma ilha - o que é peculiar à viagem é o fato de ela se cobrir mais uma vez e de novo, de tornar impossíveis o conquistado, a flacidez, a mandriice, o sétimo dia; o que é peculiar à viagem é o perigo, o inacabado, o acaso, a emergência do que não foi projetado; o que é peculiar à viagem está para além de mapas, roteiros e astrolábios. Ainda que eles sejam apetrechos necessários que formam um conjunto de possibilitadores do traçado de um percurso, enquanto eles dominam o processo, a viagem não se realiza. $\mathrm{O}$ que é peculiar à viagem são as ventanias, que trazem o ritmo inesperado do dia. Nesse mundo movediço de incertezas e espantos, na ilha, o que é peculiar à viagem é, somente, a travessia.

Quanta concentração para se chegar a algumas frases que o pensador poético não precisa esclarecer! Quanta concentração para dizer que, com todos os riscos, o futuro está para ser criado, e nós também estamos entregues aos caprichos da criação! Quanta concentração até chegar à explosão de uma frase como essa: "Mesmo sem naus e sem rumos,/mesmo sem vagas e areias,/ há sempre um copo de mar/ para um homem navegar"!" A viagem não começa, portanto, quando um barco singra a diretriz de certo rumo marítimo, mas quando a diagonal de legibilidade atuante da linguagem inventa uma saída que nosso mundo não oferecia, cria um futuro jamais antevisto, abre uma porta onde se apalpava um muro sólido. A viagem começa na força incisiva da aprendizagem da existência de um copo de mar, e na intensa dedicação à sua criação que, ela sim, recriará o navegante.

Não são apenas os habitualmente chamados poemas, como este de Jorge de Lima, que, no lugar do extensivo, privilegiam o intensivo - decisivamente, não é de uma questão de gêneros literários que se trata, nem mesmo, obviamente, de gêneros teóricos ou filosóficos. Pensar poeticamente (pelo menos, o que aqui se chama de poeticamente) pode ser tarefa dos poetas, mas é também dos filósofos, que, com aqueles, sulcam conjun- 
tamente um leito de indelimitação para que novos fluxos, imprevisíveis, de múltiplos volumes e velocidades, possam correr. Nesse mundo em que tudo está em movimento, a linguagem que se desloca pela indelimitação entre o poético e o filosófico deve substituir em si mesma a força rígida, estrutural, do construtivismo por um fluidismo que lhe é inerente.

Inventando um dos estilos de pensamento mais fecundos no que diz respeito ao corte da vida moderna, Montaigne desenrola uma multiplicidade de tópicos que vai surgindo como numa conversação consigo mesmo, sabendo, entretanto, que será escutado por terceiros, e cria, com isso - mediado pelo livro, é importante dizer -, uma tensão entre um diálogo velado com um público virtual e um pseudo-solilóquio. Nesse jogo tensivo, ou, caso se prefira, especular, reside a tangente de legibilidade atuante daquele que não escreve para erguer um monumento em praça pública nem uma estátua em uma igreja - que não visa uma multidão nem uma solidão em busca de transcendência -, mas para compor uma obra de linguagem que, através da impressão, destina-se a ocupar um lugar entre outras obras, conquistando um leitor amigo, daqueles que querem passar o tempo na diversão fraterna de uma possível vizinhança de descoberta do pensamento.

Os Ensaios são escritos pelo signo da amizade daqueles que estão abertos a se deixarem ser afetados pela palavra pensada que os desperta, numa ambiência em que leitores e escritor, nunca se encontrando onde eles mesmos se procuram, são transformados pela estranheza do livro, da qual passam a ser íntimos... Íntimos da própria estranheza de uma reindividuação a cada instante renovada, provocada pelos Ensaios. Afirmativa da alegria da amizade, calcada na encruzilhada entre a força de atração e a de propulsão que o livro é capaz de engatilhar e, com ela, balear saudavelmente o leitor, a escrita é, desde o início, um combate corporal contra a tristeza de uma solidão insatisfeita.

Sob a abrangência casual da expansividade ensaística, na qual há evidentemente uma diversa distribuição dos pesos das múltiplas idéias que vão surgindo e sucessivamente se transformando ao sabor da ébria inconstância do mundo, sem nenhuma ânsia de esgotamento de qualquer assunto, Montaigne a risca com a intensidade ímpar de uma linguagem privilegiadamente concisa, sentenciosa, segura como poucas dos efeitos que está gerando. Por essa linguagem, o livro se autodesigna 
- Montaigne, Michel de. Ensaios. Trad. Por Sérgio Milliet. São Paulo: Abril Cultural, 1972. Ensaios I , capí tulo XXVIII, Da amizade. Coleção Os Pensadores: 95.$)$

(Capítulo X, Dos que im provisam e dos que se prepa ram para falar: 29.)

\footnotetext{
- (Ensaios II, capítulo XVIII Do desmentido: 309)

- (Capítulo X, Dos livros: 196)

(: 196)
}

• (Ensaios III, capítulo III, Da companhia dos homens, das mulheres e dos livros: 382 .) uma sereia, ou melhor, citando Horácio, como o faz Montaigne*, como o corpo de uma bela mulher com cauda de peixe: em qualquer um dos casos, um ser vivo gerado pelas palavras que, escapando completamente ao banal, inventa uma linha de antecipação criadora em relação a ele, obrigando-o a ser repensado, revivido com uma nova intensidade, à luz e à sombra das palavras produtoras; assim, ele acata uma sobreposição de pedaços desconjuntos que, sem comporem um todo lógico ou obrigatório, deixam em aberto as vias de estranheza para a aproximação de um leitor que terá, minimamente que seja, de algum modo, de ajudar a pavimentá-la, para poder percorrê-la e deixar-se ser levado.

No lugar das garantias da sabedoria, um elogio - não apenas irônico - à ignorância; no lugar das certezas, os produtos da imaginação, da fantasia, capazes de organizar e canalizar alguns de seus devaneios; em vez da gravidade e da seriedade, a beleza e o requinte; em troca da explicação, da elucidação ou da demonstração, a mostra de um tipo de pensamento que não precisa justificar a si mesmo o que pensa; contrariamente a um esforço de ordenação, uma atitude assumida de desordenamento; não um projeto temático, mas a permissão para que o acaso guie seus assuntos e delineamentos da escrita, uma permissão para que o acaso guie a si mesmo (“[ [...] não me domino por completo. O acaso é meu senhor"); ; substituindo o esforço cansativo e triste da erudição, a tranqüilidade de quem, no sossego, leva uma vida serena, sem aborrecimentos, vivendo em fidelidade ao motor criativo que se apodera de si enquanto pessoa e que, dessa relação de autenticidade criativa - geradora dos Ensaios-, pode dizer: "Fez-me o meu livro, mais do que eu o fiz; e autor e livro constituem um todo"*; contra a preparação exaustiva de um conhecimento completo de determinado assunto ("não quero pagar o elevado preço que custa")", a improvisação, como no jazz e no chorinho; no lugar de uma escrita da verdade, uma outra, encontrando nos livros "o prazer de um honesto passatempo".

Vale lembrar que tal estudo voltado para o prazer, ou prazeroso justamente por não ter a obrigação de se voltar para algo predeterminado, típico de quem vive "ao sabor do momento", é conquistado por aquele que, primeiramente, estudou visando brilhar, em seguida, alcançar a sabedoria e, só no estágio mais avançado de sua vida, por pura distração, sem querer tirar qual- 
quer proveito utilitário ou dignificante de tal tarefa, ou seja, finalmente, pelo puro prazer, com a respectiva escrita de fruição das instabilidades que lhe é apropriada. Aqui, o prazer não é o ponto de partida de uma trajetória, mas o ápice de uma experiência de transformações que culmina com a aquiescência completa do acaso inestancável, de modo que o próprio escritor, partícipe do movimento de tudo o que existe, com tudo, se movimenta, apresentando uma vida que teria um de seus méritos na descoberta do passar do tempo, do avançar da própria idade, como a medida da conquista de uma liberdade cada vez maior da linguagem.

Enquanto a trajetória filosófica historicamente mais respeitável se caracterizava pela articulação de modelos de imitação que coibiam a valorização da mutabilidade sensível, Montaigne abre passagens para o trânsito de humores corporais singulares que, apresentando suas curiosas diferenças, insuflam outras individualidades a caminhos ainda não pisados. Os Ensaios são a força de produção de quem os escreve, liberando-o de qualquer estacionamento; a ambigüidade é válida, já que eles produzem (a mobilidade de) quem os escreve, mostrando, simultaneamente, desse, sua força de produção; mas, pelos mesmos motivos, eles também são a força de produção de quem os lê.

Dentre vários aspectos que poderiam ser privilegiados como as características inaugurais do ensaísmo, esses mencionados, vindos do século XVI para mostrar que o que menos importa ao pensamento é o cronológico, que certos modos de pensar possuem uma virtualidade que os permite ser presentificados a qualquer momento, resumem alguns dos campos de força de maior fecundidade atualizados pelo pensamento contemporâneo. Para os que confiam nos efeitos da linguagem, talvez haja, entretanto, um outro aspecto cuja encenação, mesmo que implicada nos itens mencionados, seja tão ou mais decisiva do que eles: a fragmentação. Entre tantas linhas possíveis de imensa apreciação, vêm daí algumas das mais belas de Montaigne, difusoras da idéia de que a obstinação intelectual, por se debruçar árdua e repetidamente sobre alguma dificuldade de pensamento até, por fim, estar supostamente apto a entendê-la, mostrandose inteiramente ineficaz, é, para ele, mera perda de tempo. Sua inclinação é pela imediaticidade da percepção intelectual: 
" (Ensaios II, capítulo X, Dos livros: 197).
As dificuldades com que deparo lendo não me preocupam exageradamente; deixo-as de lado após tentar resolvê-las uma ou duas vezes. Se me detivesse nelas, perder-me-ia e perderia meu tempo, pois meu espírito é de tal índole que o que não percebe de imediato menos entende em se obstinando. Não sou capaz de nada que não me dê prazer ou exija esforço, e atardar-me demasiado em um assunto, ou nele me concentrar demoradamente, perturba minha inteligência, cansa-a e me entristece. Embaciase a vista e se enfraquece, de modo que tenho de interromper a leitura e repeti-la, como quando queremos perceber o brilho de certos tecidos, e precisamos olhá-los várias vezes e de vários modos. Se um livro me entedia, pego outro e só me dedico à leitura quando não sei que fazer; e o enfado me domina*.

Um leitor cuja recepção depende do impacto ferrenho, decisivamente imediato, que as palavras alheias provocam em sua sensibilidade pensante e no abandono do enfado inaproveitável conseqüente da impotência de uma obstinação compreensiva retardada não tem de apostar nas leituras demoradas da inteligência das quais, por serem para ele aborrecidas, é incapaz, mas na violência casual do golpe certeiro, mais do que despojado, do fragmentário, quando pode, a cada momento, ser rapidamente afetado e, simultaneamente, interromper a leitura a seu bel-prazer, retomando-a, depois, sem o menor prejuízo.

Desinteressado de um arquivo memorial do passado, esse leitor, lendo para riscar uma linha de futuro desconhecida, enxerga nos livros lidos um pré-texto para a efetuação de suas próprias meditações, para a elaboração de relatos, a cada linha, experimentais, móveis, que, em vez de um ensinamento detentor de qualquer núcleo de saber, buscam contingências favoráveis da sorte. Inócuo, um texto incapaz de provocar novas e próprias reflexões merece ser rapidamente abandonado. Para esse leitorescritor, leitor ativo por excelência, os pensamentos que utilizam explicações lógicas, deduções e outras inutilidades que querem mastigar os fatos para nós como se fôssemos filhotes de aves incapazes de nos alimentar por nosso próprio esforço e impotentes para voar, servindo apenas àqueles que, cheios de tempo a perder, não atingiram a maturidade, hão de ser sarcasticamente ironizados.

Veja-se a excelência irônica manifestada pelas frases com que, em certo momento, alveja Platão, um dos filósofos mais artísticos de todos os tempos: "Lamento o tempo que perde, em vãs interlocuções preparatórias, um homem que tinha tanta 
coisa importante a dizer. Minha ignorância justificará sem dúvida o desprazer que me causa seu estilo"*. Se Platão, que é um homem que tinha tanta coisa importante a dizer, e, por isso mesmo, digno de leitura, recebe uma crítica como essa, em outros, que utilizam vãs interlocuções preparatórias, não se deve, nem se consegue, prestar a mínima atenção, já que, através de uma convenção frívola e insignificante, o que eles fazem é tão somente instigar o sono ou, quando muito, um silêncio descortês e estúpido ou, ainda, insuflar nada mais do que tolices:

São bons para a escola, o tribunal, o púlpito onde temos tempo de cochilar e ainda reatar o discurso ao despertarmos um quarto de hora depois. Assim é que se fala aos magistrados quando se deseja ganhar uma causa, com ou sem razão; ou às crianças, ou à multidão, às quais é preciso tudo dizer e repetir para que entendam alguma coisa. Mas eu não quero que me gritem cinqüenta vezes: "ouça bem isso"*.

No lugar de infantilizar o leitor, repetindo-lhes, incansavelmente, com ar de superioridade professoral, suas hipotéticas obrigações, um pensamento poético efetivo tem de possuir a força para estimular o movimento, excitar a caminhada do trabalho, ativar a criação de novas diagonais de legibilidade atuantes, de novas linhas de antecipação. Para apagar uma escrita debilitada e debilitante, prenhe do palavrório de preâmbulos cansativos e desencantadores, Montaigne, criticando simultaneamente os poderes educacionais, legislativos e religiosos, instaura um outro tipo de escrita (os próprios Ensaios): nele, não se arrasta esfomeadamente em torno de uma questão, mas começa brutalmente já pelo fim, atacando, desde o início, o ponto principal do problema, talvez com a linguagem mais coloquial da filosofia, completamente isenta de qualquer pretensiosidade lingüística: "Condimentos e molhos não me agradam pois gosto de carne crua”. Carne crua de uma palavra que, vascular e viva, se cortada, sangra, como, a propósito de Montaigne, escreveu, para sempre, Emerson: "Cut these words, and they would bleed; they are vascular and alive"*.
"(Ibid. Ensaios II, capítulo X, Dos livros: 197)

" (Ibid. Ensaios II, capítulo X, Dos livros: 199.)

" (Emerson, Ralph Waldo. "Montaigne; or, the Skeptic". Em: Representative Men, 1850.) 


\section{Alberto Pucheu}

Nascido em 1966, Alberto Pucheu é professor de Teoria Literária da UFRJ e poeta. Escritos da indiscernibilidade(Azougue Editorial, 2003), $A$ vida é assim e Ecometria do silêncio estão entre seus livros publicados. Organizou o livro Poesia (e) Filosofia; por poetas-filósofos em atuação no Brasil.

Palavras-chave poesia e filosofia fragmentação Montaigne

Keywords poetry and philosophy fragmentation Montaigne

\section{Resumo}

Uma das características daqueles que pensam poeticamente é a confiança nos efeitos da linguagem. Sem a violência de um sentido inesperado sobre a pessoa, sem a coação desse prévio exterior a impor um lance de confusão ao que era interior, sem esse impacto de uma subitaneidade desestruturante das fixidades, não há poético. Nesse lance de confusão, vazador da linha de exclusão entre exterior e interior, nessa instauração de uma zona de mútua permeabilidade, principia o pensamento. No que aqui interessa, tal pensamento poético ocorre tanto nos poetas como nos filósofos que, com aqueles, sulcam um leito de indelimitação entre eles para que um novo fluxo, imprevisível, de múltiplos volumes e velocidades, possa correr. Inventando um dos estilos de pensamento mais fecundos no corte da vida moderna, Montaigne resume alguns dos campos de força de maior intensidade atualizados pelo pensamento contemporâneo. Entre eles, a fragmentação, cuja encenação é decisiva.

\section{Abstract}

One of the characteristics of those who think poetically is to trust the effects of language. Without the violence of an unexpected sense over somebody, without this previous outer experience provoking confusion to what was before an inner experience, without this force breaking up whatever used to be static, there is no poetic. Poetic thought springs up from this confusion between an outer and an inner experience and from the setting up of a mutual permeability zone. Likewise, poetic thought occurs as much to poets as to philosophers, and they together furrow a riverbed of many possi-

\section{Résumé}

Une des caractéristiques de ceux qui pensent poétiquement est la confiance faite aux effets du langage. Sans la violence d'un sens inattendu sur la personne, sans la contrainte de ce préalable extérieur jettant la confusion sur ce qui était intérieur, sans cet impact d'un tout à coup déconstruisant les fixités, il n'y a pas de poétique. Dans ce coup d'embarras qui renverse la ligne d'exclusion entre l'extérieur et l'intérieur, instaurant une zone de permeabilité réciproque, commence la pensée. Quant à ce qui intéresse ici, une telle pensée poétique a lieu tantôt chez le poètes tantôt chez les philosophes qui, avec ceux-là, 
bilities so that a new and unpredictable stream of multiple volumes and velocities can flow continuously. Creating one of the most fruitful and intensive styles of modern life, Montaigne anticipates many thoughts brought up to date by contemporary thought. For instance, the fragmentation, style in which his performance is decisive. creusent un lit de non délimitation entre eux pour qu'un nouveau flot imprévisible de multiples volumes et vitesses puisse avoir lieu. Inventeur d'un des styles de pensée les plus féconds dans le découpage de la vie moderne, Montaigne résume quelques-uns des champs de force de plus grande intensité actualisés par la pensée contemporaine. Parmi eux, la fragmentation, dont la mise en scène est décisive.
Recebido em $31 / 08 / 2003$ Aprovado em $12 / 09 / 2003$ 